\title{
US vs. China Which Country Did a Better Job in Containing COVID-19?
}

\author{
Zhangsiwen Yue $^{1}$ \\ ${ }^{1}$ School of Education, University of Washington, Seattle, WA, 98105, USA \\ College of Liberal Arts, Pennsylvania State University (world campus) \\ Email: ysiwen@uw.edu
}

\begin{abstract}
The COVID-19 pandemic has caused the deaths of hundreds and thousands, casting an unprecedented public health crisis that impacted government regulations, national economy, and the research and development of new technologies. As leading powers of the world, the United States and China put forth various safety precautions, expansionary economic policies to put the nations back on their feet in their unique ways. This study aims to understand the impacts of the COVID-19 pandemic on specific spectrums that entails the government's role in controlling the virus, the economy, and technology in China and the United States. At the same time, the study servers to analyze the difference between the two countries in the ways they dealt with the COVID-19 situation through the areas mentioned above and why these disparities occur through synthesizing previous findings of related topics. Analysis of the political environment between China and the United States was adopted to compare the difference between government regulation methods. The supply and demand model was used to evaluate expansionary economic practices and their effects on both countries. Lastly, a cost-effectiveness analysis was selected to understand the efficacy of technologies developed in both countries to combat the virus. After close inspection, it found that China has achieved better results in virus control through government regulation than the United States under its unique political environment that enables a timely response. Both the United States and China have adopted economic recovery practices that are suitable for their country. The technology innovation in the COVID-19 vaccine and vaccination rate of the United States is worth learning and recommended in China.
\end{abstract}

Keywords :COVID-19, Economic impact, Technology, Government Regulation

\section{INTRODUCTION}

With the uprising of the global pandemic caused by the novel COVID-19 virus, different responses to treatments of different countries have become a useful testament to the effectiveness of each country's healthcare system. In particular, the sharp contrast between the United States and China in the way they responded to this pandemic is being widely discussed in modern media, reflecting their drastically different health plans and medical care while inevitably uncovering their advantages and loopholes. Noticing that the healthcare system cannot stand alone without the heavy impact of the country's political climate, economy, and technology, it is critical to examine a country's performance on the COVID-19 pandemic in these three aspects.
In the United States, COVID-19 has revealed some glaring flaws about the US health care system in the following spectrums: The US had a relatively slow response to deal with COVID-19. When COVID-19 first started, the CDC (Centers for Disease Control) did not advice people to wear a mask and transmitted false information that the virus is not air born. The government also did not enforce rules on social distancing, quarantine, and the closing of non-essential businesses. Citizens at that time are also unaware of the seriousness of the infection and did not take proper precautions to prevent the virus from spreading. This results in a surge of COVID-infected cases in the US, which puts huge pressure on the US's already flawed public health system. For example, the defects in the disease prevention system caused a severe shortage of masks, sanitizers, gloves, and other personal protective equipment. The hospitals, too, did not have enough 
medical supplies such as beds and ventilators and doctors to treat the patients, which further exacerbates the outbreak. Because of the lack of healthcare equity and the high cost of treatment, many underprivileged people choose not to get treatment, contributing to the death count and the spreading of the disease [1]. Fortunately, the United States is implementing precautionary rules to mitigate the impact of the disease. Shortly after the inauguration of President Joe Biden, America had witnessed a drastic change in the preestablished healthcare system under the legislation of former President Donald Trump. Biden's platform issued ten executive orders to combat the COVID-19 since he took office on January $20^{\text {th }}, 2021$. These changes include the effort of giving Americans a new choice of health insurance, which allows working-age adults, in addition to elderlies, to purchase public insurance plans instead of private ones; expanding the coverage to blue-collar workers and low-income citizens; eliminating surprise billing and market concentration; restricting regulation of price setting as well as allowing consumers to buy foreign prescription drugs [2]. To combat COVID-19, the US government also produced effective tracking technologies, vaccination, and economy stimulating strategies to recover from the damages of the pandemic. The healthcare system in China also impeded the spreading of diseases. Noticing that the supply of doctors is abundant, and they are capable of treating three or four times more patients than doctors in the US, and they generally earn significantly less. Therefore, patients can get treated quicker and at a lower cost. Furthermore, medical insurance in China covers a wide range of expenses and is mostly mandatory, which alleviates the financial burden of the patients, encouraging them to get medical care. As a result, in China, the newly detected cases are limited to no more than ten per day [3]. However, China's health care system was built on a strict socialist society where the power of governmental control is high, resulting in a recovery plan heavily reliant on restriction, surveillance, and scrutinization. Is this the best way to handle the negativities of the pandemic? The answer is complicated. Perhaps a middle point of China's and the US's approach is needed to produce the best outcome.

\subsection{Related Work}

According to the health care systems of each country and their comparisons, I divided the existed work into three categories.

\subsubsection{Healthcare system in the US}

The previous research found that the United States healthcare system is flawed due to high medical costs, putting marginalized groups into further despair, especially during COVID-19. As Michael [4] claimed, administrative costs in the United States have been estimated to represent 34.2 percent of total healthcare expenditures, which is a proportion twice as much as that found in Canada in 2017. Similarly, In the article 'America's health care crisis is much deeper than COVID-19', Madara [5] found that the healthcare system has exacerbated the inequities despite the technological advancements. Those favor some groups while unfairly disadvantages the others, who are people of color, LGBTQ community, people living in rural areas, and poor people. Gee [6] found that the high outof-pocket costs, uninsured rate, and the low medical staff supply had made the United States extremely vulnerable to the coronavirus. The author further sees that many Americans may avoid medical care even for serious conditions like being infected by the coronavirus due to the high cost.

\subsubsection{China's healthcare system}

Earlier articles found challenges and opportunities in China's healthcare system. According to Wee [7], many desperate patients diagnosed with cancer seek help by purchasing unauthorized homemade cancer drugs due to China's troubled health care system. China's basic insurance plan does not cover the surging costs of treatment for chronic disease and drugs, putting many families in despair. Furthermore, foreign drugs have to go through an extensive vetting process to get approval while still risking denial of payment from insurance companies. China's challenge is not alone. Many pharmaceutical companies in America also face regulatory hurdles and approval delays, preventing patients from getting the help they need. Apart from the challenges that China faces in terms of accessibility, advanced technologies are found effective for COVID19 treatment of prevention. Sun et al. [8] found that the Chinese government had used innovative technologies such as 5G, big data analysis, cloud computing, and artificial intelligence to monitor infected persons on their health conditions and track their locations to help China win the fight against COVID-19.

\subsubsection{US and China healthcare system comparison}

Guo [9] made a comparison between the healthcare system in China and the United States. Through interviewing both Chinese and American patients, she saw that receiving treatment in the United States takes longer than that in China. Yet, this is not the case because long lines of patients waiting outside of the hospital overnight are common in large cities like Beijing, Shanghai, and Guangdong. Scalpers did business selling high price tickets to patients who are desperate to get treatment, making healthcare more expensive. 


\subsection{Objectives}

In this paper, I will be comparing the United States and China's attitudes towards controlling the COVID-19 pandemic by presenting each country's governmental regulation on safety precautions, economic recovery methods, and technology innovation. At the same time, I will be analyzing the differences in the areas mentioned above and how the differences occur. At last, I will conclude with the strengths and weaknesses of the countries' policies and practices that serve to combat the virus.

\section{GOVERNMENT REGULATION}

As a result of the novel coronavirus, governmental interventions have played an important role in preventing the spread of the virus. Specifically, the Chinese government has done an exemplary job in this effort. From the diagnosis of the first infected case in Wuhan until nowadays, the Chinese government adopted precautionary measures immediately through gathering center for disease control and preventions, hospitals, pharmaceutical manufacturers, and scientific institutions to act as a united team to combat the epidemic. Together, with effective emergency executive orders and policies and the collaboration of the people, China was able to significantly reduce the number of infected cases within several months.

\subsection{Safety Measures that the Chinese government Adopted During the Outbreak}

\subsubsection{City lock-down and Mandatory Self- Quarantine}

Since January $23^{\text {rd }}$, 2020, Wuhan Municipal Party Committee cast an order to close down the city of Wuhan, which suspended public transportations including taxi, bus, subway, highway, ferry, and plane rides, banning the citizens of Wuhan from exiting the city and visitors from entering. At the same time, mandatory stay home orders are executed, limiting visits to public arenas except for seeking medical help and obtaining daily necessities. Shortly after Wuhan's closure, many cities in China followed its footsteps in implementing traffic control measures, cancelling large social gatherings, and reducing operating capacities of non-essential businesses. In particular, as the heart and most populated city of China, Beijing has paid extra attention to limiting the number of incomers to reduce the potential risk of introducing viruses from other cities to infect a greater number of people. To ensure that citizens of China are following the necessary precautions, the Chinese government placed orders on local neighborhood communities to monitor and report the visited locations and purpose of activities of their residents and their body temperatures every time they enter the neighborhood. Once the neighborhood committee discovers any resident with symptoms of infection or is suspected of having contacted sickened personnel, a noteworthy sign will be placed on the resident's home door to notify other residents that he or she may be infected. Sometimes, security guards will be placed in the resident's home door to ensure that the suspected resident is not leaving the house within fourteen days. In this case, groceries will be delivered to the door via online shopping or the help of the neighborhood committee. Starting from April 2020, Chinese citizens who seek to return to China from abroad and foreigners who wish to visit China for essential business have to undergo strict medical examination and isolation.

\subsubsection{Wearing Masks in public places becomes mandatory}

Before the COVID-19 outbreak, mask wearing is always seen as an effective measure to prevent the spread of illness and mitigate the impact of pollution in China. However, masks had been mandatory when the pandemic first started circulating in tandem with other safety measures such as hand washing and social distancing. Compulsory face masks wearing also changed many traditions and habits. For example, China's communal eating culture that involves every student sitting at the same table and picking out shared food is changed. During the pandemic, middle and high school students in China have to take turns eating lunch if they are sitting close where one student would have to wait wearing face masks until the other student finishes eating [10].

\subsubsection{Making COVID tests and treatments affordable and accessible to all}

To encourage patients to seek medical help in a timely manner, the Chinese government announced that the government and medical insurance cover the medical expenses for the testing and treating COVID-19. To make sure that every patient gets the care they needed, the Chinese government decided to construct temporary sanctuaries by shifting sports arenas and train stations into hospitals, housing more than 20,000 [11] beds for patients who cannot be admitted to regular hospitals. In addition, two emergency hospitals are opened in the city of Wuhan with the name of Leishenshan Hospital and Huoshenshan Hospital. Together, the two hospitals provided over 93,900 [9] square meters of spaces effective for social distancing practices and over 2600 [11] beds for patients with moderate to severe symptoms. Furthermore, the Wuhan Municipal Government repurposed hotels and university dormitories to quarantine those who came in contact with infected cases or have been infected. To address the severe shortages of medical supplies and staff, the 
Wuhan government sent emergency signals to the Chinese Party Central Committee to dispatch medical support teams from other cities to join Wuhan in their fight against the virus along with respirators and personal protective equipment [11].

To find a cure for the COVID-19 pandemic, the Chinese government had spent a large portion of its expenditure to fund research and development for scientific institutions and universities. Key contributors include research teams from the Chinese Academy of Sciences, Chinese Academy of Medical Sciences, and Tsinghua University. They are leading efforts in virus tracing, vaccine production, and drug selection. Within a year, the Chinese National Medical Products Administration approved the manufacturing of COVID vaccines after a series of strict scrutinization. Currently, more than one hundred million Chinese citizens had received the first dosage of the vaccine, taking a vital step towards achieving immunization [12].

\subsection{US and Chinese government regulation comparison}

To compare the government's regulating power for China and the United States, one would have to analyze the difference in a different society where each country belongs. I would argue that whether one exceeds the other depends on the situation. Powerful government is perhaps the most efficient solution to ensure the continuity of a sovereign if this is what we are prioritizing. It is easier to establish power and ensure the stability of a country through a single authoritative figure, who often has the power to intervene in a situation through indisputable commands. On the other hand, in democratic countries, it is hard to establish a dictatorship since there are so many voices that could potentially pose disagreement or, even worse, outright rebellion against the government.

Taking the COVID-19 situation as an example, China and America reacted to this situation reflects the huge disparity between the method of governance. When the outbreak first started, the Chinese government took action immediately though commanding the closing of city Wuhan, which is where the virus is discovered, and ordered everybody to quarantine and that masks are mandatory in public areas. Everyone did exactly what they were told, so the virus got contained within two months after discovering the first infected case, and that major cities like Beijing and Shanghai were not severely affected. In China, the newly detected cases are limited to no more than ten per day these days. On the other hand, America failed to control the virus after one year, and the cases are still surging until today. This has to do with the government's lack of saying in the decision making of its people since democracy emphasizes freedom of individuality. This makes it hard for people to agree with each other and act uniformly towards a common goal. For instance, while some people agreed that wearing a mask could protect ourselves and others from the virus, others argue that their right to breathe fresh air is removed. Therefore, when it comes to making important decisions requiring collaboration between the people, an effective government could act faster and more efficiently than democratic countries.

On the other hand, democracy has its advantage when it comes to human rights. It opens more options for its people to choose from, one of them being that democracy gives people a chance to become personally involved with their government. Because the government in a democracy is under the control of the people and their voice, it is up to everyone to decide their fate. People can choose to vote in whatever way their morality desire. Some even give voters the option to not vote if that is what they feel is the best way to express their opinion. For instance, most Americans voted for President Biden because their morality aligned with what Biden stand up for. In comparison, the election process for the Chinese president is not disclosed to the public, so that people cannot determine if the leader's policies work best for them, which could encourage tyranny when all the power lies within the government.

\section{ECONOMIC IMPACT}

\subsection{Cash distribution in the $U S$}

In the United States, the economic impact of the pandemic is reflected in the demand and supply of many small businesses such as restaurants, travel industries (public transportation, airlines, hotels, Airbnb, etc.) As more people are spending more time eating at home to eliminate the spread of the virus, the demand for eating in restaurants decreases (from D to D'). On the supply side, because there are fewer customers, the restaurant business faces bankruptcy as they cannot get enough income to pay for their employees, such as waiters and cooks. They are also forced to downsize, resulting in a decrease in supply (from $S$ to $S$ '), causing a decrease in equilibrium quantity and a potential decrease in price. The same economic impact is also cast in the travel industry. To stimulate the economy and encourage spending, the government distributes emergency tax relief funds as Trump signed into law $\$ 8.3$ billion in emergency funding to fight COVID-19. $\$ 950$ million is provided for state and local public health departments used for hiring, buying equipment, and improving data analytics during March 2020 [13]. The government also issue loans for small business hurt by the lockdown such as the travel and dining industry. With government subsidy, a small business can reopen and operate under limited capacity. At the same time, people who received tax relief have greater consumption power, which would 
facilitate the recovery of the economy as it increases both demand (from D' to D') and supply (from S' to $\mathrm{S}$ ').

\section{Market of restaurant business before government subsidy}

\section{Price}

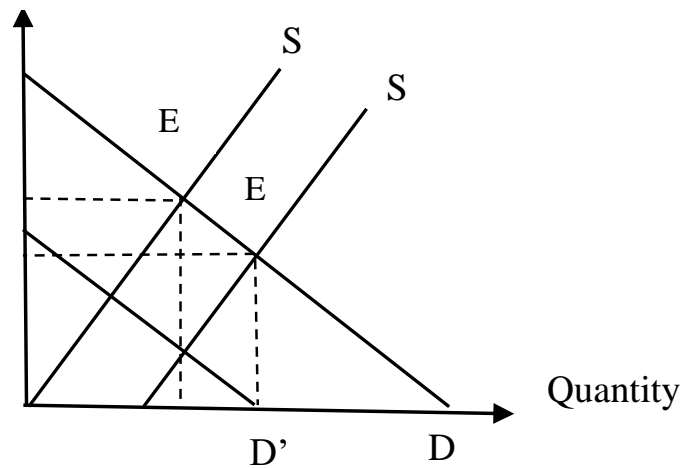

\section{Market of restaurant business after government subsidy}

Price

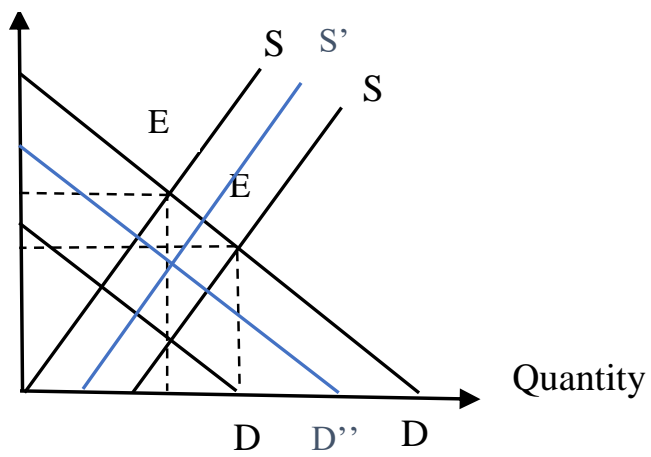

\subsection{Consumer Vouchers issuance in China}

Chinese people's consumption habits had been significantly altered since the awakening of the COVID19 outbreak. According to China's Central Bank, there is a $6.6 \%$ increase in bank deposits during the first quarter of 2020 compared to the same period of 2019. There is also a $19 \%$ decrease in spending on consumer goods, as suggested by the National Bureau of Statistics.

To mitigate the negative economic impact that the pandemic had on China, the Chinese government adopted a different method from the United States as a part of their recovery plan by distributing consumer vouchers. The Consumer Voucher are digital coupons issued by the local city government to citizens to help them buy groceries, clothes, foods, and other necessities [14]. The coupons can be redeemed on popular Chinese point-of-purchase apps such as WeChat and Alipay.
However, the coupons can be used to purchase almost any kind of goods and services except for buying financial products, lotteries, paying for loans, and utility bills. These vouchers come with a "first come, first serve" and "take it or lose it" basis, meaning that there is a limited amount available for people to obtain each day and a set time window of when it can be used. Furthermore, the vouchers cannot be exchanged for cash or deposited into bank accounts [15]. To further stimulate consumption activities, some vouchers are assigned with a designated amount of spending to be used, for example, a two for one deal, while the amount is usually quite small ranging from 10 to 80 Yuan with an expiration date [14]. Until May $8^{\text {th }}, 2020$, more than 170 cities had issued coupons totaling a face value of more than 19 billion Yuan [16].

\subsection{Economic Recovery Methods Comparison}

Clearly, both the United States and China's recovery methods had their advantages and shortcomings. China, under the background of a socialist command economy where the government was able to regulate production and consumption, handing out vouchers was able to effectively boost consumer spending in the industries where they believe that needed help in coronavirus's wake, for instance, tourism, restaurants, and entertainment. In Wuhan, where the virus was first discovered, most of its coupons are applied to restaurants, shopping centers, and supermarkets since these are the businesses that are most severely destroyed by the outbreak [17]. Consumers would be motivated to buy more goods and services from the declining business with the same price by issuing consumption coupons, which increases demand, prompting more production, thereby stimulating the economy. At the same time, with the linkage of the coupons to point-ofpurchase Apps, the government could review the consumer's transaction history through its database and track down the items that are purchased to monitor if the consumer is spending their money on what they need. By putting on restrictions on the coupon, the government also ensured that citizens would not exchange the coupons for cash, which disables the government from tracking or depositing it the bank, which defeats encouraging market activities.

The United States, on the other hand, would not have benefited from the voucher policy as China did because of the different spending political climate and spending habits. In the US, where the savings rate is significantly lower than that of China, handing out vouchers would put people into further despair when they do not have the money to use the voucher in the first place since many vouchers require consumers to spend at least a certain amount. Under this circumstance, distributing cash is the most effective way to help people increase purchasing power as they would most 
likely spend what they receive immediately when they do not have enough savings. Yet, the downside of cash distribution would be that the government loses regulation power over people's consumption decisions. This may encourage many to put their money into bad use, such as the purchase of drugs and alcohol, which are markets that do not need stimulation. Additionally, because China and the United States are at different phases in combating the virus, a different regulating protocol is needed. While China has achieved nearly zero infection, the government needs to entice everyone to open their wallets and go out shopping to recover the damp economy; the United States is still experiencing spikes in infection rates. Thus, lending out cash serves to encourage quarantines and limit unnecessary social contacts, which is the direct opposite of what China is trying to achieve.

Yet, the policy of consumer vouchers has noteworthy defects. For example, it failed to account for low-income families in who the COVID-19 outbreak and senior citizens have most severely impacted. Due to the reason that most vouchers are distributed through digital payment platforms like WeChat and Alipay that usually requires the beneficiary to have access to a mobile device rather than through paper coupon, it is difficult for poor families to acquire. Meanwhile, senior citizens are often unfamiliar with the usage of cell phones, let alone searching for a valid voucher before they are all gone. Besides that, while vouchers may support consumer spending, they are not very helpful to impoverished families. Because poorer families do not have money to use the voucher living in rural areas where shopping centers that most vouchers can be spent are far away. The strategy also inconvenienced elderlies who are incapable of traveling. On the other hand, distributing cash seemed to be a simpler and more direct method to help those who are struggling financially as it requires no technical skills or problems of accessibility.

\section{TECHNOLOGY INNOVATION}

\subsection{Technologies in China}

\subsubsection{Tracking Devices}

The rising new technologies also contributed momentously to the prevention and curing of diseases. Positioning technologies, specifically, had grown to be increasingly popular in China during the outbreak. BeiDou, as one of China's GNSS constellations, was designed to pinpoint the riskiest areas to help medical professionals locate carry out rehabilitation efforts promptly; it also helped with tracking patients and infected areas, thereby containing the virus [18].

\subsubsection{Robotics}

The use of robotics is also prevalent in restaurants, public transportations, hospitals, and hotel lobbies. From delivering meals to severely infected patients, transporting medical samples to spraying disinfectants in the subway, increasing the number of helping hands as waiters in the restaurant, robots were on the front line to prevent the spread of the virus. A hospital in Wuhan, for example, is operated entirely based on robotic technologies. They can do the initial screening for patients and carry food and medicines to patients from doctors without human contact [18].

\subsubsection{Health Rating System}

The Chinese government joined efforts with tech giants like Alibaba in developing a health rating system that is a cell phone app that tracks millions of people daily. The system is linked with each person's medical record and places that the person traveled to. It assigns people with colors: green, yellow and red, depending on whether they had traveled to a highly infected area or country and health condition. The color then determines whether the person will be allowed in public spaces, with green being allowed, yellow being needing further investigation, and red being not allowed [18].

\subsubsection{Mask Making Machines}

As the biggest mask manufacturer globally, China expedited mask production to cater to the rising demand for masks amid the pandemic by urging factories to transfer their businesses. BYD, an energy vehicle manufacturing company, has transformed its work into creating mask-making machines, which added 100 mask production lines to the market. With each production line making over 50,000 masks a day, BYD can generate 5,000,000 masks and 300,000 bottles of disinfectants daily, which alleviated the shortage of masks in China and the world [19].

\subsection{Technologies in the U.S}

\subsubsection{Exposure Tracking Technology}

The United States adopted similar methods to protect its citizens from catching the diseases. Tech giants Google and Apple forged a partnership and released their new COVID-tracking APP as a novel technology for sending exposure alerts to users' smartphones if the user had come in contact with others who were tested positive. Additionally, the APP also allows infected users to send warnings to everyone within the area without revealing personal identity. This technology has gained popularity after six months after its first release, as recently, approximately $21 \%$ of the US population have access to it [20]. 


\subsubsection{Telemedicine}

To effectively limit in-person contact and expand treatment capacity, the United States also adopted Telemedicine, a technology used by many hospitals across the nation, allowing doctors to screen, treat and prescribe medicines to patients remotely. Telemedicine is integrated with telemedicine software enabling doctors to retrieve patients' medical records. AI diagnosis then provides more accurate diagnoses and treatments, and medical streaming devices monitor patients' health conditions in real time [21].

\subsubsection{COVID-19 Vaccination}

Finally, the greatest achievement that the United States had accomplished during its fight against the pandemic is, without doubt, the production of the first approved mRNA inoculations used on humans. This medical breakthrough signifies a new era of vaccinology where mRNA vaccinations have become the future trend. Thanks to Moderna and Pfizer-BioNTech, the two biotechnology companies that have created the novel COVID-19 vaccine completed and passed the human trials and emergency use authorization and have gained a promising $94.1 \%$ and $95 \%$ efficacy in their products [22].

\subsection{Technology Comparison}

The United States and China have both developed and implemented innovative technologies to improve people's awareness about their exposure to the disease and better assist the practicability of safety persuasions. Yet, the technologies themselves vary and carried out different effects: China's technologies mostly involve tracking devices that are mandatory for people to download and robotics to help those already infected. The United States focused on developing a cure for the disease and optimize people's personal choices on enrolling in the technologies. Perhaps this is another reason China could contain the virus significantly faster than the United States by offering citizens no other ways but to collaborate with the government but have not yet created vaccination breakthroughs like the United States.

Nevertheless, China was able to successfully implement and execute its technologies with the country's proven technique on industrial robotics and digital payments. Research indicates that 87,000 units of industrial robots were sold across the country in 2016, which accounted for 30 percent of the global market, whereas Europe and the US combined had 97,300 units [23]. More so, China had adopted digital payment far earlier than the United States. Since 2013, the Chinese have been using WeChat Pay as the primary payment method. It benefits the merchants as they pay as little merchant fee as 0.6 percent and make transactions more convenient for consumers for not carrying around cash and cards, which could activate the spread of the virus. In North America, on the other hand, the average cardpresent fee is as high as 2.2 percent, contrasting sharper as merchants there are paying significantly more to process fewer transactions comparing to China [24]. High card fees also decrease purchasing power for consumers. They end up paying for goods and services for a higher price because sellers' fees to Visa and MasterCard are built into the retail price, which hurts the already stagnate economy the pandemic.

Besides digital technology and robotics, medical breakthrough also marks the victory against the virus. Both the United States and China had produced COVID-19 vaccinations but with different methodologies and effects. Moderna and PfizerBioNTech of the US use mRNA vaccines. This approach involves injecting the virus's genetic material into muscular tissue that triggers protein production in the human body, thereby generating antibodies against the real virus. On the other hand, Sinovac, a biopharmaceutical company based in Beijing, adopted the traditional vaccine production method, which requires the injection of a weakened or inactivates virus into the human body to trigger an immune response. mRNA vaccines, in this case, were proven to be more effective than traditional vaccine as mRNA vaccines in the US have a $94.1 \%$ to $95 \%$ efficiency rate after two doses while traditional vaccines in China has as a $79 \%$ efficiency rate after two doses [25]. Meanwhile, the cost of one dose of Pfizer vaccine is expected to cost $\$ 19.5$ per dose while that of China is claimed to cost $\$ 29.75$ per dose[26]. With the given data, the cost effectiveness analysis between the Pfizer COVID-19 vaccine and the Sinovac COVID-19 vaccine can be conducted through the calculation of Incremental Cost-Effectiveness Ratio (ICER) as follows:

ICER Pfizer.Sinovac $=\frac{(\text { cost of Pfizer- cost of Sinovac })}{(\text { Effectiveness of Pfizer- Effectiveness of Sinovac })}$
$=\frac{2 *(\$ 19.5 / \text { dose }-\$ 29.75 / \text { dose })}{(95 \%-79 \%)} \approx \$-1.28 /$ percent of efficacy.

In this case, a negative ICER value suggested that the Pfizer vaccine is more effective and saves more money comparing to the Sinovac vaccine. Therefore, vaccines of the United States is more cost effective than China's.

Other advantages of mRNA vaccine over conventional vaccines include lower cost of production, high production speed, and the introduction of both cellular and humoral immunity [27].

\section{CONCLUSION}

In conclusion, China has been proved it had successfully won the fight against the pandemic while the war for the United States is still ongoing. Through the government's direct control in marshalling early 
lockdowns, mandatory safety precautions, coupled with the right economic stimulating policies and technological advancements, China has made the correct response for China's socialist market economy. However, the problems faced by the United States suggest that a different approach is needed. In the journey to beat the virus, the United States had made noteworthy progress in providing breakthroughs in vaccinology, effectively eliminating the spread of the virus domestically and internationally. Yet, more potent governmental regulation is needed to ensure that safety measures are properly carried out and strictly adhered to. Therefore, judging from governmental regulation, economic recovery, and technological advancement, both countries had a lot to learn from each other as China requires more advancement on vaccination and comprehensive economic policies that helps the poor. At the same time, the United States needs stronger governing power.

\section{REFERENCES}

[1] Regan (2021). COVID-19 revealed how sick the US health care delivery system really is. https://theconversation.com/covid-19-revealedhow-sick-the-us-health-care-delivery-systemreally-is-153614

[2] Williams (2021). Public option in Biden plan could change the face of US health care. https://theconversation.com/public-option-inbiden-plan-could-change-the-face-of-us-healthcare-153816

[3] AlTakarli N, S: China's Response to the COVID-19 Outbreak: A Model for Epidemic Preparedness and Management. Dubai Med J 2020;3:44-49. doi: 10.1159/000508448

[4] Michael, E. (2020, January 6). A third of US health care spending stems from administrative costs. Retrieved January 27, 2021, from https://www.healio.com/news/primarycare/20200106/a-third-of-us-health-care-spendingstems-from-administrative-

costs\#: :text=In\%202017\%2C\%20\%24812\%20bill ion $\% 20 \% \mathrm{E} 2 \% 80 \% 94 \% 20 \% 242 \% 2 \mathrm{C} 497$,of\%20nat ional $\% 20$ health $\% 20$ care $\% 20$ expenditures.\&text=In surer's $\% 20$ overhead $\% 20$ was $\% 20$ considerably $\% 20$ higher, \%24146\%20per\%20capita\%20in\%20Canad a

[5] Madara. L (2020, July 22). America's health care crisis is much deeper than COVID-19. https://www.ama-

assn.org/about/leadership/america-s-health-carecrisis-much-deeper-covid-19
[6] Gee, E., Spiro, T. (2019, April 8). Excess Administrative Costs Burden the U.S. Health Care System. Retrieved March 27, 2021, from https://www.americanprogress.org/issues/healthcar e/reports/2019/04/08/468302/excessadministrative-costs-burden-u-s-health-caresystem/

[7] Wee, S. (2018, November 11). In China, Desperate Patients Smuggle Drugs. Or Make Their Own. Retrieved January 27, 2021, from https://www.nytimes.com/2018/11/11/business/chi na-drugs-smuggled-homemade.html?auth=logingoogle

[8] Sun, S., Xie, Z., Yu, K. et al. COVID-19 and healthcare system in China: challenges and progression for a sustainable future. Global Health 17, 14 (2021). https://doi.org/10.1186/s12992-02100665-9

[9] Guo. J. (2017, March 28). How does healthcare in the U.S. compare with China's? https://supchina.com/2017/03/28/healthcare-uscompare-china/

[10] Koetse (2020, April 10). Schools in China Are Reopening, But Will Lunch Breaks Ever Be the Same Again? https://www.whatsonweibo.com/schools-in-chinaare-reopening-but-will-lunch-breaks-ever-be-thesame-again/

[11] Chinese National Health Commission. Press conference record. Available from: http://www.nhc.gov.cn/xwzb/webcontroller.do?titl eSeq $=11209 \&$ gecstype $=1$. Accessed April 10, 2021.

[12] How many people have received vaccination? Experts published data showing progress towards total immunity (2021, April 8) https://baijiahao.baidu.com/s?id=16964838247634 $07565 \& w f r=$ spider $\&$ for $=$ pc. Accessed April 10, 2021.

[13] Moeller, \& Oresman. (2020). COVID-19 (Coronavirus) Emergency Funding and Tax Relief: Assessing Federal Opportunities. Pillsbury Law. From https://www.pillsburylaw.com/en/news-andinsights/covid-19-emergency-funding-and-taxrelief-assessing-federal-opportunities.html.

Accessed April 10, 2021.

[14] Weedon, \& Yang. (2020) https://www.abc.net.au/news/2020-0423/coronavirus-china-coupon-stimulus-economicrecovery/12169520 
[15] Lin and Chen (June 16,2020). Did the Consumption Voucher Scheme Stimulate the Economy? Evidence from Smooth Time-Varying Cointegration Analysis. file://C:/Users/rober/Downloads/sustainability-1204895.pdf

[16] Cheng, \& Guo (2020). In Depth: Who really benefits from China's consumption vouchers? https://asia.nikkei.com/Spotlight/Caixin/In-DepthWho-really-benefits-from-China-s-consumptionvouchers

[17] Jiefang Daily (2020, May 27).Why doesn't China distribute cash like developed countries? Are consumer vouchers working? https://baijiahao.baidu.com/s?id=16677946207810 $54377 \& w f r=$ spider $\&$ for $=$ pc. Accessed April 10, 2021.

[18] Chaturvedi (2020). The China way: Use of technology to combat Covid 19 https://www.geospatialworld.net/article/the-sinoapproach-use-of-technology-to-combat-covid-19/

[19] China Daily (2020). Chinese car maker BYD starts engine on mask production. https://www.chinadaily.com.cn/a/202003/16/WS5e 6f6501a31012821727f7db.html\#: :text=For\%20ea ch\%20mask\%2Dmaking\%20machine, make\%2050 $\% 2 \mathrm{C} 000 \% 20$ masks\%20a\%20day.

[20] Leswing (2020). States are finally starting to use the Covid-tracking tech Apple and Google built here's why. https://www.cnbc.com/2020/10/03/covid-appexposure-notification-apple-google.html

[21] Vsee. What Is Telemedicine? https://vsee.com/what-is-telemedicine/\#4

[22] Chicago Today (2021). Pfizer vs. Moderna Vaccines: Side Effects, Efficacy and More. https://www.nbcchicago.com/news/local/pfizer-vsmoderna-vaccines-side-effects-efficacy-andmore/2490162/

[23] Cheng et al (2019). The Rise of Robots in China. https://doi.org/10.1257/jep.33.2.71. Accessed April, 24, 2021

[24] Eckler (2021). Digital Payment in China Are Cheap and Convenient. https://www.practicalecommerce.com/digitalpayments-in-china-are-cheap-and-convenient. Accessed April, 24, 2021

[25] BBC News (2021). Covid: What do we know about China's coronavirus vaccines? https://www.bbc.com/news/world-asia-china55212787

[26] Terry (2021). UPDATED Comparing COVID-19 Vaccines: Timelines, Types and Prices. https://www.biospace.com/article/comparingcovid-19-vaccines-pfizer-biontech-modernaastrazeneca-oxford-j-and-j-russia-s-sputnik-v/

[27] Peters(2020). What are the advantages of an mRNA vaccine for COVID-19? https://massivesci.com/articles/mrna-vaccinecovid19-coronavirus-moderna/ 